\title{
Outcome Prediction in Patients of Traumatic Brain Injury Based on Midline Shift on CT Scan of Brain
}

\author{
Shrikant Govindrao Palekar ${ }^{1} \quad$ Manish Jaiswal2,๑ \\ ${ }^{1}$ Department of General Surgery, Dr. Vasantrao Pawar Medical \\ College, Hospital \& research center, Adgaon, Nasik, India \\ 2Department of Neurosurgery, King George's Medical University, \\ Lucknow, Uttar Pradesh, India \\ ${ }^{3}$ Department of Neurosurgery, Tirunelveli Government Medical \\ College, Tamil Nadu, India
}

\author{
Mandar Patil ${ }^{3} \quad$ Vijay Malpathak ${ }^{1}$
}

Indian J Neurosurg 2021;10:210-215.

\author{
Address for correspondence Manish Jaiswal, MCh, Department of \\ Neurosurgery, King George's Medical University, Lucknow \\ 226003, Uttar Pradesh, India \\ (e-mail: manishjaiswal@kgmcindia.edu).
}

\begin{abstract}
Keywords

- traumatic brain injury

- midline shift in CT scan brain

- Glasgow coma scale
\end{abstract}

Background Clinicians treating patients with head injury often take decisions based on their assessment of prognosis. Assessment of prognosis could help communication with a patient and the family. One of the most widely used clinical tools for such prediction is the Glasgow coma scale (GCS); however, the tool has a limitation with regard to its use in patients who are under sedation, are intubated, or under the influence of alcohol or psychoactive drugs. CT scan findings such as status of basal cistern, midline shift, associated traumatic subarachnoid hemorrhage (SAH), and intraventricular hemorrhage are useful indicators in predicting outcome and also considered as valid options for prognostication of the patients with traumatic brain injury (TBI), especially in emergency setting.

Materials and Methods 108 patients of head injury were assessed at admission with clinical examination, history, and CT scan of brain. CT findings were classified according to type of lesion and midline shift correlated to GCS score at admission. All the subjects in this study were managed with an identical treatment protocol. Outcome of these patients were assessed on GCS score at discharge.

Results Among patients with severe GCS, 51\% had midline shift. The degree of midline shift in CT head was a statistically significant determinant of outcome $(p=0.023)$. Seventeen out of 48 patients (35.4\%) with midline shift had poor outcome as compared with 8 out of 60 patients (13.3\%) with no midline shift.

Conclusion In patients with TBI, the degree of midline shift on CT scan was significantly related to the severity of head injury and resulted in poor clinical outcome.

\section{Introduction}

Head injury is a silent epidemic that has paramount shortand long-term consequences. To allow proper resource allocation (which is of preeminent importance in developing countries), there is a need for such a system that correctly predicts the outcome.

Traumatic brain injury (TBI) is a complex injury caused by a sudden trauma to the brain or by an object piercing the

published online January 21, 2021
DOI https://doi.org/ 10.1055/s-0040-1716990 ISSN 2277-954X. brain tissue in which a broad spectrum of symptoms and disabilities can be observed. ${ }^{1}$ It is one of the major causes of death and disability. Predicting an outcome after head injury is difficult, and it is therefore rightly described in the Hippocratic maxim, "No head injury is too severe to despair of, nor too trivial to ignore."

Clinicians treating patients often take decisions on the basis of their assessment of prognosis. As much as $80 \%$ of

(c) 2021. Neurological Surgeons' Society of India.

This is an open access article published by Thieme under the terms of the Creative Commons Attribution-NonDerivative-NonCommercial-License, permitting copying and reproduction so long as the original work is given appropriate credit. Contents may not be used for commercial purposes, or adapted, remixed, transformed or built upon. (https://creativecommons.org/licenses/by-nc-nd/4.0/).

Thieme Medical and Scientific Publishers Pvt. Ltd. A-12, 2nd Floor, Sector 2, Noida-201301 UP, India 
doctors believe that an assessment of prognosis in a head injury patient is important for taking therapeutic decisions such as barbiturates, hyperventilation, or mannitol. Assessment of prognosis could help communication with a patient and the family. ${ }^{3}$

One of the most widely used clinical pearls for such prediction is the Glasgow coma scale (GCS). ${ }^{4}$ However, its major shortcoming is the limitation of its use among patients who are under sedation, under the influence of alcohol or psychoactive drugs, or are intubated. ${ }^{5-9}$ This hindrance has been compensated with the use of the morphological criteria based on radiological imaging. MRI studies are limited in terms of detecting white matter changes in the late phase..$^{10,11}$ Hence, in the current scenario, scoring models based on CT imaging remains the valid option for prognostication of patients with TBI.

CT scan characteristics such as status of basal cistern, ${ }^{9}$ midline shift, ${ }^{12-14}$ traumatic subarachnoid hemorrhage $(\mathrm{tSAH}),{ }^{15-17}$ and intraventricular hemorrhage ${ }^{18}$ are useful indicators in predicting outcome in TBI.

So, we planned a prospective study to analyze the correlation between degree of midline shift on CT scan of brain and GCS score on admission in prediction of possible clinical outcome in head injury, in order to correlate CT scan finding of head injury patient with GCS of the patient and evaluate age, site of injury, type of injury and pupillary reaction as contributory factors in predicting outcome.

\section{Materials and Methods}

This study was conducted at our tertiary care center. A total of 108 patients with head injury admitted in trauma ward and ICU in the stipulated duration of study were enrolled in this study.

The duration of study was between January 2019 and June 2019. The study was prospective in nature. The following criteria were set to include and exclude patients in this study.

\section{Eligibility Criteria}

Inclusion Criteria: All patients with recent onset traumatic head injuries coming to casualty and outpatient

Exclusion Criteria: Patients on anticoagulant therapy or having any coagulopathy, Patients with preexisting intracranial lesions.

All patients with recent history of head injury coming to outpatient and casualty were enrolled in the study. All patients enrolled were evaluated immediately on admission. This was followed by clinical history and physical examination. GCS scoring, pupil size and it's response \& signs of base of skull fractures were documented. CT head was done as soon as the patient was stabilized. The type of brain injury was noted along with the presence and amount of midline shift. Subsequently, neurological assessment of patients was done from admission till discharge. The interval of neurological assessment for patients with GCS score equal to 15 were followed, starting after the initial assessment in the emergency department: half-hourly for 2 hours, then 1-hourly for 4 hours, and 2-hourly thereafter. If patients with GCS score equal to 15 deteriorated at any time after the initial 2-hour period, neurological assessment interval was reverted to half-hourly and original frequency schedule was followed. Operative decisions were taken as per latest brain trauma foundation guidelines. ${ }^{19}$ Patients in whom surgical intervention was not required were managed conservatively with serial neurological assessment as described above, and antiepileptics and antiedema measures were given as recommended in the latest brain trauma foundation guidelines. ${ }^{19}$

The final outcome at discharge was divided into two groups on the basis of Glasgow outcome scale (GOS) scores as described below:

1. Good outcome: Recovery with no or moderate disability.

2. Poor outcome: Patients with severe disability, vegetative status, or death.

The GCS-hospital discharge (GOS-HD) is a useful prognostic index in patients with TBI, as it predicts long-term outcome at time of discharge which helps in rehabilitation.

Patients with moderate-to-severe disability were asked to follow-up on OPD basis at 1-month interval from discharge and mild disability at 3 months from discharge. The total duration of follow-up for each group was approximately 6 months.

\section{Statistical Analysis}

Statistical analysis was performed using the computational program statistical analysis system (SAS), for Windows, version 8.2. Descriptive analysis was done by constructing frequency tables for categorical variables and position and dispersion measures for continuous variables. To verify the existence of associations or to compare proportions between selected variables, $\chi 2$, McNemar, or Fisher's exact tests were employed as fitted. To verify the most important factors that have influenced patients' outcome, logistic regression analysis was employed. The results were considered statistically significant when $p<0.05$.

\section{Results}

The results were derived from pooled data of 108 patients with TBI. The study took into account the age, sex, cause of head injury, type of brain lesion, midline shift on CT scan of brain, pupillary reaction and GCS score as clinical outcome predictors in patients with head injury.

Majority of the patients in the study were within the age group of 21 to 40 years (51.8\%), followed by 41 to 60 years (28.7\%) but this difference was considered to be not statistically significant ( $p>0.05$; - Table 1 ).

In our study, road traffic accidents (RTA) was the most common cause of head injury (76\%), followed by fall (15\%) and assault (9\%). RTA was the most common cause of head injury in age groups of 0 to 20 years, 21 to 40 years and 41 to 60 years, while fall being the most common cause in elderly (>60 years).

Out of these 108 patients in the study, 88 (81\%) were male and 20 (19\%) females. This difference was found not significant on statistical analysis ( $p$ value $=0.8278 ;-$ Table 2 ). 
CT scan of brain showed multiple lesions in most patients, but for the purpose of classification of head injury in this study, the dominant lesion was considered. The present study showed no abnormality in 16 patients, while the rest had common intracranial hemorrhage like subdural hemorrhage $(n=44)$, extradural hemorrhage $(n=21)$, intracerebral hemorrhage ( $n=14)$, and subarachnoid hemorrhage (SAH) $(n=8)$. Five patients had diffuse axonal injury with no intracranial hemorrhage ( - Table 3 ).

In our study, 60 patients had no midline shift on CT scan of brain, while 30 patients had midline shift of less than $5 \mathrm{~mm}$, and 18 patients had shift of more than $5 \mathrm{~mm}$ (-Table 4). RTA had maximum incidence of mass effect in the form of midline shift (53\%).

If the type of brain lesion is taken into account with respect to mass effect, that is, midline shift, then subdural hemorrhage was most commonly associated with midline

Table 1 Age-wise distribution

\begin{tabular}{|l|l|l|l|l|l|}
\hline $\begin{array}{l}\text { Age, in } \\
\text { years }\end{array}$ & $\begin{array}{l}\text { Good } \\
\text { outcome }\end{array}$ & $\begin{array}{l}\text { Poor } \\
\text { outcome }\end{array}$ & Total & $\begin{array}{l}\text { Chi- } \\
\text { square }\end{array}$ & - value \\
\cline { 1 - 4 }-20 & 6 & 1 & 7 & & \\
\cline { 1 - 4 } $21-40$ & 46 & 10 & 56 & \multirow{2}{*}{$\mathbf{3 . 0 3 6 3}$} & \multirow{2}{*}{$\mathbf{0 . 4 4}^{\text {a }}$} \\
\cline { 1 - 4 } $41-60$ & 22 & 9 & 31 & \\
\hline$>60$ & 9 & 5 & 14 & & \\
\hline Total & 83 & 25 & 108 & & \\
\hline
\end{tabular}

aStatistically, no significant value.

Table 2 Sex distribution

\begin{tabular}{|l|l|l|l|l|l|}
\hline Sex & $\begin{array}{l}\text { Good } \\
\text { outcome }\end{array}$ & $\begin{array}{l}\text { Poor } \\
\text { outcome }\end{array}$ & Total & Chi-square & $\boldsymbol{p}$-Value \\
\hline Male & 68 & 20 & 88 & $\mathbf{0 . 0 5}$ & $\mathbf{0 . 8 2 7 8}^{\mathrm{a}}$ \\
\cline { 1 - 3 } Female & 15 & 5 & 20 & & \\
\hline Total & 83 & 25 & 108 & & \\
\hline
\end{tabular}

aStatistically, no significant value.

Table 3 CT head findings and outcome

\begin{tabular}{|c|c|c|c|c|c|}
\hline $\begin{array}{l}\text { CT head } \\
\text { finding }\end{array}$ & $\begin{array}{l}\text { Good } \\
\text { outcome }\end{array}$ & $\begin{array}{l}\text { Poor } \\
\text { outcome }\end{array}$ & Total & Chi-square & $p$-Value \\
\hline Normal & 16 & 0 & 16 & \multirow[t]{9}{*}{15.96} & \multirow[t]{9}{*}{$0.025^{a}$} \\
\hline SDH & 10 & 2 & 12 & & \\
\hline EDH & 8 & 1 & 9 & & \\
\hline $\mathrm{SAH}$ & 7 & 1 & 8 & & \\
\hline $\mathrm{ICH}$ & 11 & 3 & 14 & & \\
\hline $\begin{array}{l}\text { SDH with } \\
\text { shift }\end{array}$ & 19 & 13 & 32 & & \\
\hline $\begin{array}{l}\text { EDH with } \\
\text { shift }\end{array}$ & 10 & 2 & 12 & & \\
\hline DAI & 2 & 3 & 5 & & \\
\hline Total & 83 & 25 & 108 & & \\
\hline
\end{tabular}

Abbreviations: $\mathrm{CT}$, computed tomography; $\mathrm{SDH}$, subdural hematoma; DAl, diffuse axonal injury; EDH, extradural hematoma; SAH, subarachnoid hematoma; ICH, intracerebral hematoma.

aStatistically significant value. shift with incidence of almost $75 \%$ followed by extradural hemorrhage (52\%). In the present study, CT scan of brain showed no midline shift in patients with SAH and diffuse axonal injury (-Fig. 1).

GCS score of patients was also associated with an amount of midline shift in the present study. Out of 21 patients of head injury with mild GCS, six patients (29\%) had midline shift; out of 18 patients with moderate GCS, seven patients (39\%) had midline shift; and out of 69 patients with severe GCS, 35 patients (51\%) had midline shift (- Table 5).

Pupillary reaction was also taken into consideration, which showed $27 \%$ patients with bilaterally equal reacting pupils had midline shift as compared with $100 \%$ patients with unequal pupils had midline shift, while $40 \%$ patients with bilaterally nonreacting pupils had midline shift (-Table 6).

In our study, 18 out of 108 patients of head injury got operated for craniotomy. Out of these 18 patients, 13 patients had subdural hematoma, three patients had intraparenchymal bleed/contusion, one patient had extradural hematoma, and one patient had diffuse axonal injury with medically refractory cerebral edema. Among the operated patients, 14 patients had anisocoria and four patients had bilaterally unequal nonreacting pupillary reaction.

When the midline shift was taken into consideration, three patients had midline shift less than $5 \mathrm{~mm}$, while the rest had more than $5 \mathrm{~mm}$. The patients with midline shift less than $5 \mathrm{~mm}$ were decided for surgical management on the basis of severe GCS score, anisocoria, and presence of clot size more than $30 \mathrm{~mL}$. Postoperative deaths were three out of 18 patients.

Table 4 Midline shift in CT head and outcome

\begin{tabular}{|c|c|c|c|c|c|}
\hline $\begin{array}{l}\text { Midline } \\
\text { shift in CT }\end{array}$ & $\begin{array}{l}\text { Good } \\
\text { outcome }\end{array}$ & $\begin{array}{l}\text { Poor } \\
\text { outcome }\end{array}$ & Total & Chi-square & $p$ value \\
\hline No shift & 52 & 8 & 60 & \multirow[t]{4}{*}{7.505} & \multirow[t]{4}{*}{$0.023^{a}$} \\
\hline$<5 \mathrm{~mm}$ & 20 & 10 & 30 & & \\
\hline$\geq 5 \mathrm{~mm}$ & 11 & 7 & 18 & & \\
\hline Total & 83 & 25 & 108 & & \\
\hline
\end{tabular}

Abbreviation: $\mathrm{CT}$, computed tomography.

aStatistically significant value.

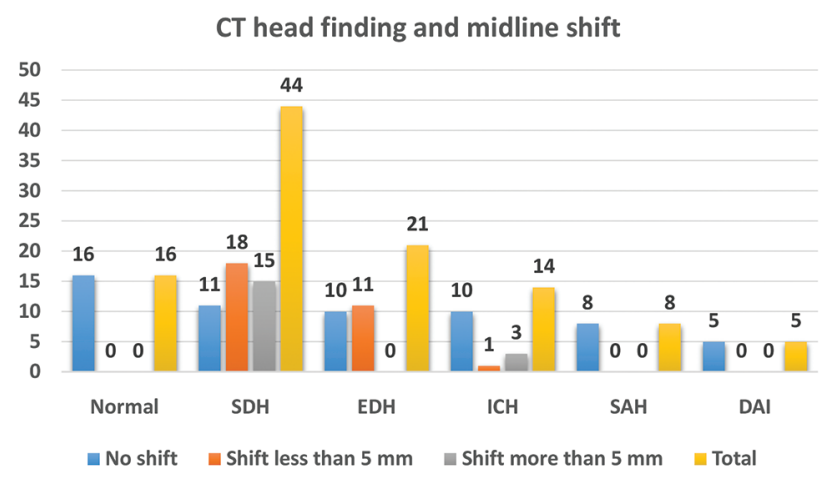

Fig. 1 Computed tomography (CT) head finding and midline shift in $C T$. DAI, diffuse axonal injury; $E D H$, extradural hematoma; ICH, intracerebral hematoma; SAH, subarachnoid hematoma; SDH, subdural hematoma. 
Table 5 Midline shift in CT head and GCS

\begin{tabular}{|l|l|l|l|l|}
\hline \multirow{2}{*}{$\begin{array}{l}\text { Midline shift } \\
\text { in CT head }\end{array}$} & \multicolumn{4}{|c|}{ GCS } \\
\cline { 2 - 5 } & Mild & Moderate & Severe & Total \\
\hline No shift & 15 & 11 & 34 & 60 \\
\hline Shift $<5 \mathrm{~mm}$ & 5 & 5 & 20 & 30 \\
\hline Shift $>5 \mathrm{~mm}$ & 1 & 2 & 15 & 18 \\
\hline Total & 21 & 18 & 69 & 108 \\
\hline
\end{tabular}

Abbreviations: CT, computed tomography; GCS, Glasgow coma scale.

Table 6 Pupillary reaction and midline shift in CT head

\begin{tabular}{|c|c|c|c|c|}
\hline \multirow{2}{*}{$\begin{array}{l}\text { Midline } \\
\text { shift in CT } \\
\text { head }\end{array}$} & \multicolumn{3}{|c|}{ Pupillary reaction } & \multirow[t]{2}{*}{ Total } \\
\hline & $\begin{array}{l}\text { Equal } \\
\text { reacting }\end{array}$ & Unequal & $\begin{array}{l}\text { Bilaterally } \\
\text { nonreacting }\end{array}$ & \\
\hline No shift & 51 & 0 & 9 & 60 \\
\hline Shift $<5 \mathrm{~mm}$ & 19 & 8 & 3 & 30 \\
\hline Shift $>5 \mathrm{~mm}$ & 0 & 15 & 3 & 18 \\
\hline Total & 70 & 23 & 15 & 108 \\
\hline
\end{tabular}

Abbreviation: $\mathrm{CT}$, computed tomography.

Neurological outcome was dichotomized into good and poor outcome based on the GOS score. ${ }^{20}$ In the present study, 83 patients had good outcome (GOS 4 and 5) after head injury according to GOS as compared with 25 patients who had poor outcome (GOS 1, 2 and 3; - Table 7).

There were 83 patients in the good outcome group. Out of these 83 patients, midline shift of more than $5 \mathrm{~mm}$ in CT head was found only in 11 cases ( $13.25 \%$ cases). In the bad outcome group of a total of 25 patients, seven patients ( $28 \%$ cases) has more than $5 \mathrm{~mm}$ midline shift in CT head (-Table 4).

In the present study, low-GCS score at admission was associated with poor outcomes $(p=0.003)$. Among the patients with mild GCS (13 to 15 ) at presentation, 95.2\% patients had good outcome (GOS 4 and 5), while $4.2 \%$ patients had poor outcome (GOS 1, 2 and 3), in contrast to patients with severe GCS (3 to 8 ), wherein $66 \%$ patient had good outcome and $33.4 \%$ patients had poor outcome (-Table 8).

In the present study, out of 70 patients with equal reacting pupils, only 10 patients (14.3\%) had poor outcome, while $34.8 \%$ of patients with unequal pupils and $46.7 \%$ patients with nonreacting pupils on both sides had poor outcome ( - Table 9).

\section{Discussion}

The study by Kraus ${ }^{21}$ has shown that the most common group affected by head injuries are the young people between 20 years and 40 years and the incidence is lowest at extremes of age, that is, below 5 years and above 60 years. Similar findings were observed in our present study.

The most common mechanisms leading to TBI are fall accidents, RTA, and assault-related incidents as observed by Gan et al. ${ }^{22} \mathrm{~A}$ study by Chiewvit et a ${ }^{20}$ has shown that the most common cause of head injury in age group of 0 to 20 years was motor accidents; highest incidence in group of 21 to 40 years was assault with a blunt object; and in
Table 7 GOS distribution

\begin{tabular}{|c|l|}
\hline GOS score & No. of patients \\
\hline GOS 5 & 37 \\
\hline GOS 4 & 46 \\
\hline Total (good outcome) & 83 \\
\hline GOS 3 & 7 \\
\hline GOS 2 & 10 \\
\hline GOS 1 & 8 \\
\hline Total (poor outcome) & 25 \\
\hline
\end{tabular}

Abbreviation: GIS, Glasgow outcome scale.

Table 8 GCS and outcome

\begin{tabular}{|l|l|l|l|l|l|}
\hline $\begin{array}{l}\text { GCS } \\
\text { severity }\end{array}$ & $\begin{array}{l}\text { Good } \\
\text { outcome }\end{array}$ & $\begin{array}{l}\text { Poor } \\
\text { outcome }\end{array}$ & Total & Chi square & $\boldsymbol{p}$ value \\
\hline Mild & 20 & 1 & 21 & $\mathbf{1 1 . 1 4 6}$ & $\mathbf{0 . 0 0 3}^{\text {a }}$ \\
\cline { 1 - 4 } Moderate & 17 & 1 & 18 & & \\
\cline { 1 - 4 } Severe & 46 & 23 & 69 & & \\
\cline { 1 - 4 } Total & 83 & 25 & 108 & & \\
\hline
\end{tabular}

Abbreviation: GCS, Glasgow coma scale.

aStatistically significant value.

Table 9 Pupillary reaction and outcome

\begin{tabular}{|l|l|l|l|l|l|}
\hline & $\begin{array}{l}\text { Good } \\
\text { outcome }\end{array}$ & $\begin{array}{l}\text { Poor } \\
\text { outcome }\end{array}$ & Total & Chi-square & $\boldsymbol{p}$ value \\
\hline $\begin{array}{l}\text { Equal } \\
\text { reacting }\end{array}$ & 60 & 10 & 70 & $\mathbf{9 . 5 0 4}$ & $\mathbf{0 . 0 0 8}^{\text {a }}$ \\
\cline { 1 - 3 } Unequal & 15 & 8 & 23 & & \\
\cline { 1 - 3 } $\begin{array}{l}\text { Bilateral } \\
\text { non } \\
\text { reacting }\end{array}$ & 8 & 7 & 15 & & \\
\cline { 1 - 4 } Total & 83 & 25 & 108 & & \\
\hline
\end{tabular}

aStatistically significant value.

group of 41-60 years, car accident was the most common cause while fall was the most common etiology in the group of > 60 years. On analysis of mode of head injury, we have found that RTA was the most common cause for the same.

In the study by Kraus, ${ }^{21}$ it was shown that the incidence is more in males as compared with females and most of the studies quote an incidence of 3:2 in favor of males. Ratio of male female in our study came out to be $4: 1$, indicating males are affected more than female, and this finding is similar to other studies. Age and sex are important predictors of outcome in head injury. As shown in the study by Gan et $\mathrm{al}^{22}$ which concluded that the mortality rate of the elderly group was significantly more, as much as more than double than that of the younger group. Hence, age can be considered an important factor in predicting outcome in the elderly with TBI.

In the study by Slewa-Younan et $\mathrm{al}^{23}$ although identical admission criteria was applied to both sexes, the levels of injury 
severity in males were greater than females. Other authors state that the association was apparent only after the age of 40 years $^{3,24}$ and especially above 60 years. ${ }^{25}$ There is no association between outcome in patients with head injury and age lower than 40 years. ${ }^{3,26} \mathrm{~A}$ plausible explanation for this may be comorbidities due to old age other than intracranial injury, senile changes in brain like increased plasticity and cortical atrophy, or differences in clinical management in the elderly group. ${ }^{3}$ Surprisingly, Fabbri et $\mathrm{a}^{26}$ in their analysis did not find age to be associated with outcome in patients with head injury, in contrast with a few reports. Similarly, in the present study, age and sex were no significant predictors of outcome $(p>0.05)$.

Strong evidence was found for the midline shift,,${ }^{14,27-29}$ and increasing size of the shift was associated with poorer outcome. ${ }^{30}$ Jacobs et $a l,{ }^{31}$ in their study of 605 patients with moderate-to-severe head injuries concluded that midline shift is a significant predictor of outcome. They did not find any cutoff mark in midline shift; rather it was a continuous variable. They also concluded that type of lesion was also significant in predicting outcome. The prognosis in patients with similar midline shift after intracranial injuries was better for patients with an extradural hematoma, as compared with those with acute subdural hematoma. 12,27,32

The present study concluded that the degree of midline shift in patients' brain injury was a statistically significant determinant of outcome $(p=0.023)$. Seventeen out of 48 patients (35.4\%) with midline shift had poor outcome as compared with eight out of 60 patients (13.3\%) with no midline shift.

Gennarelli et $\mathrm{al}^{33}$ and Lobato et $\mathrm{a}^{34}$ in their study concluded that the type of intracranial lesion is an important factor in predicting outcome, as the severity of injury is assessed by GCS scores. In the present study, the type of injury was significantly associated with outcome of patients with head injury $(p=0.025)$. Diffuse axonal injury had the worst results with $60 \%$ patients having poor outcome while extradural hematoma patients had better results with $11 \%$ patients having poor outcome. Also, patients of subdural hematoma with midline shift had poorer outcome (41.6\%) than patients having extradural hematoma with midline shift (16.7\%).

According to the literature, there is strong evidence for the prognostic value of the GCS score on admission to hospital and the GCS motor score. ${ }^{25,28,35,36}$ Lower admission GCS and lower GCS motor scores were associated with worse outcomes. ${ }^{26,35,36}$ The GCS showed a clear linear relation with mortality. ${ }^{3}$

There exists a relation between absence of or abnormal pupillary reactions and worse outcomes in TBI. ${ }^{28,36}$ Pupil abnormalities were noted more frequently in patients with mass lesions, compressed cisterns, and shift, and more in patients with CT class III/IV than in patients with CT class I/II. ${ }^{37}$

\section{Conclusion}

The increasing degree of midline shift on CT scan of brain in patients with mass lesions after TBI was significantly related to the severity of head injury (GCS $=3-12$ ) and eventually resulted in poor clinical outcome. The maximum number of patients on presentation were found to have severe head injury (GCS < 8). Prognosis of patients worsens with decreasing GCS score. The type of head injury also plays a significant role in outcome prediction. By correlating CT scan finding with GCS score, we can predict the severity of head injury and a possible outcome of patient more accurately than considering both parameters as separate entities.

\section{Funding}

None.

\section{Conflict of Interest}

None declared.

\section{References}

1 Thurman DJ, Alverson C, Dunn KA, Guerrero J, Sniezek JE. Traumatic brain injury in the United States: a public health perspective. J Head Trauma Rehabil 1999;14(6):602-615

2 Hukkelhoven CW, Steyerberg EW, Habbema JD, et al. Predicting outcome after traumatic brain injury: development and validation of a prognostic score based on admission characteristics. J Neurotrauma 2005;22(10):1025-1039

3 Perel P, Arango M, Clayton T, et al; MRC CRASH Trial Collaborators. Predicting outcome after traumatic brain injury: practical prognostic models based on large cohort of international patients. BMJ 2008;336(7641):425-429

4 Teasdale G, Jennett B. Assessment of coma and impaired consciousness. A practical scale. Lancet 1974;2(7872):81-84

5 Balestreri M, Czosnyka M, Chatfield DA, et al. Predictive value of Glasgow Coma Scale after brain trauma: change in trend over the past ten years. J Neurol Neurosurg Psychiatry 2004;75(1):161-162

6 Buechler CM, Blostein PA, Koestner A, Hurt K, Schaars M, McKernan J. Variation among trauma centers' calculation of Glasgow Coma Scale score: results of a national survey. J Trauma 1998;45(3):429-432

7 Eisenberg HM, Gary HE Jr, Aldrich EF, et al. Initial CT findings in 753 patients with severe head injury. A report from the NIH Traumatic Coma Data Bank. J Neurosurg 1990;73(5):688-698

8 Malec JF, Brown AW, Leibson CL, et al. The mayo classification system for traumatic brain injury severity. J Neurotrauma 2007;24(9):1417-1424

9 Narayan RK, Greenberg RP, Miller JD, et al. Improved confidence of outcome prediction in severe head injury. A comparative analysis of the clinical examination, multimodality evoked potentials, CT scanning, and intracranial pressure. J Neurosurg 1981;54(6):751-762

10 Firsching R, Woischneck D, Klein S, Reissberg S, Döhring W, Peters B. Classification of severe head injury based on magnetic resonance imaging. Acta Neurochir (Wien) 2001;143(3):263-271

11 Uchino Y, Okimura Y, Tanaka M, Saeki N, Yamaura A. Computed tomography and magnetic resonance imaging of mild head injury-is it appropriate to classify patients with Glasgow Coma Scale score of 13 to 15 as "mild injury"? Acta Neurochir (Wien) 2001;143(10):1031-1037

12 Servadei F, Nasi MT, Giuliani G, et al. CT prognostic factors in acute subdural haematomas: the value of the 'worst' CT scan. Br J Neurosurg 2000;14(2):110-116

13 Azian AA, Nurulazman AA, Shuaib L, et al. Computed tomography of the brain in predicting outcome of traumatic intracranial haemorrhage in Malaysian patients. Acta Neurochir (Wien) 2001;143(7):711-720 
14 Pillai SV, Kolluri VR, Praharaj SS. Outcome prediction model for severe diffuse brain injuries: development and evaluation. Neurol India 2003;51(3):345-349

15 Mattioli C, Beretta L, Gerevini S, et al. Traumatic subarachnoid hemorrhage on the computerized tomography scan obtained at admission: a multicenter assessment of the accuracy of diagnosis and the potential impact on patient outcome. J Neurosurg 2003;98(1):37-42

16 Ono J, Yamaura A, Kubota M, Okimura Y, Isobe K. Outcome prediction in severe head injury: analyses of clinical prognostic factors. J Clin Neurosci 2001;8(2):120-123

17 Servadei F, Murray GD, Teasdale GM, et al. Traumatic subarachnoid hemorrhage: demographic and clinical study of 750 patients from the European brain injury consortium survey of head injuries. Neurosurgery 2002;50(2):261-267, discussion 267-269

18 Maas AIR, Hukkelhoven CWPM, Marshal LF, Steyerberg EW. Prediction of outcome in traumatic brain injury with CT characteristics: a comparison between the CT classification and combination of predictors. Neurosurgery 2005;57:1173-1182

19 Carney N, Totten AM, O'Reilly C, et al. Guidelines for the management of severe traumatic brain injury. Neurosurgery 2017;80:6-15

20 Chiewvit P, Tritakarn SO, Nanta-aree S, Suthipongchai S. Degree of midline shift from CT scan predicted outcome in patients with head injuries. J Med Assoc Thai 2010;93(1):99-107

21 Kraus JF, Epidemiology: In: Elizabeth F, ed. NINS. Head Injury Clinical Management and Research. Geneva, Switzerland: AIREN; 1990: 113-24

22 Gan BK, Lim JH, Ng IH. Outcome of moderate and severe traumatic brain injury amongst the elderly in Singapore. Ann Acad Med Singapore 2004;33(1):63-67

23 Slewa-Younan S, Green AM, Baguley IJ, Gurka JA, Marosszeky JE. Sex differences in injury severity and outcome measures after traumatic brain injury. Arch Phys Med Rehabil 2004;85(3):376-379

24 Hukkelhoven CWPM, Steyerberg EW, Rampen AJJ, et al. Patient age and outcome following severe traumatic brain injury: an analysis of 5600 patients. J Neurosurg 2003;99(4):666-673

25 Saadat S, Akbari H, Khorramirouz R, Mofid R, Rahimi-Movaghar V. Determinants of mortality in patients with traumatic brain injury. Ulus Travma Acil Cerrahi Derg 2012;18(3):219-224
26 Fabbri A, Servadei F, Marchesini G, Stein SC, Vandelli A. Early predictors of unfavourable outcome in subjects with moderate head injury in the emergency department. J Neurol Neurosurg Psychiatry 2008;79(5):567-573

27 Maas AIR, Steyerberg EW, Butcher I, et al. Prognostic value of computerized tomography scan characteristics in traumatic brain injury: results from the IMPACT study. J Neurotrauma 2007;24(2):303-314

28 Murray GD, Butcher I, McHugh GS, et al. Multivariable prognostic analysis in traumatic brain injury: results from the IMPACT study. J Neurotrauma 2007;24(2):329-337

29 Hiler M, Czosnyka M, Hutchinson P, et al. Predictive value of initial computerized tomography scan, intracranial pressure, and state of autoregulation in patients with traumatic brain injury. J Neurosurg 2006;104(5):731-737

30 Ho KM, Burrell M, Rao S. Extracranial injuries are important in determining mortality of neurotrauma. Crit Care Med 2010;38(7):1562-1568

31 Jacobs B, Beems T, van der Vliet TM, Diaz-Arrastia RR, Borm GF, Vos PE. Computed tomography and outcome in moderate and severe traumatic brain injury: hematoma volume and midline shift revisited. J Neurotrauma 2011;28(2):203-215

32 Bahloul M, Chelly H, Ben Hmida M, et al. Prognosis of traumatic head injury in South Tunisia: a multivariate analysis of 437 cases. J Trauma 2004;57(2):255-261

33 Gennarelli TA, Spielman GM, Langfitt TW, et al. Influence of the type of intracranial lesion on outcome from severe head injury. J Neurosurg 1982;56(1):26-32

34 Lobato RD, Cordobes F, Rivas JJ, et al. Outcome from severe head injury related to the type of intracranial lesion. A computerized tomography study. J Neurosurg 1983;59(5):762-774

35 Husson EC, Ribbers GM, Willemse-van Son AH, Verhagen AP, Stam HJ. Prognosis of six-month functioning after moderate to severe traumatic brain injury: a systematic review of prospective cohort studies. J Rehabil Med 2010;42(5):425-436

36 Marmarou A, Lu J, Butcher I, et al. Prognostic value of the Glasgow Coma Scale and pupil reactivity in traumatic brain injury assessed pre-hospital and on enrollment: an IMPACT analysis. J Neurotrauma 2007;24(2):270-280

37 Sarrafzadeh AS, Peltonen EE, Kaisers U, Küchler I, Lanksch WR, Unterberg AW. Secondary insults in severe head injury-do multiply injured patients do worse? Crit Care Med 2001;29(6):1116-1123 